\title{
A IMPORTÂNCIA DA PRESERVAÇÃO E CONSERVAÇÃO DAS ÁGUAS SUPERFICIAIS E SUBTERRÂNEAS: UM PANORAMA SOBRE A ESCASSEZ DA ÁGUA NO BRASIL
}

\author{
Érica Natasha dos Anjos Garcia ${ }^{1}$ \\ Diego Aparecido Alves Costa Moreno ${ }^{2}$ \\ André Luís Valverde Fernandes ${ }^{3}$
}

\section{RESUMO}

Atualmente, a falta de água atinge milhares de pessoas espalhadas por todo o mundo, assim como diversas regiões brasileiras que já sofrem com problemas de escassez. Nesse sentido, o presente trabalho tem por objetivo demonstrar a importância biológica, econômica e social da água, despertando a valorização da qualidade das águas superficiais e subterrâneas, com ênfase na sua preservação e conservação. A metodologia fundamentou-se na pesquisa básica e exploratória e como técnica de coleta de dados, a pesquisa bibliográfica. Percebe-se que em pleno século XXI, as pessoas de um modo em geral, ainda não se atentaram devidamente quando o assunto é problemas causados ao meio ambiente, e, sobretudo, com a escassez da água. Portanto, torna-se necessário uma mudança imediata no hábito e costumes das pessoas, sendo imprescindível inverter essa realidade, conscientizando-as e mostrando o valor e a importância dos recursos hídricos.

PALAVRAS-CHAVE: Águas superficiais e subterrâneas. Ciclo hidrológico. Escassez da água.

\section{THE IMPORTANCE OF PRESERVATION AND CONSERVATION OF SURFACE WATER AND UNDERGROUND: NA OVERVIEW ON THE WATER SHORTAGE IN BRAZIL.}

\begin{abstract}
Currently, the lack of water affects thousands of people all over the world, as well as several Brazilian regions that already suffer from shortages problems. In this direction, this paper aims to demonstrate the biological, economic and social importance of water, raising the quality appreciation of surface and groundwater, with an emphasis on preservation and conservation. The methodology is based on the basic and exploratory research and data collection on bibliographic research. It is noticed that in the XXI century, people still do not paid attention properly when it comes to the environment problems, and especially with water shortage. For that reason, it is necessary an immediate habit and customs

\footnotetext{
${ }^{1}$ Graduanda do curso de Engenharia Ambiental e Sanitária, Faculdades Integradas de Três Lagoas AEMS. E-mail: nat31@hotmail.com.

${ }^{2}$ Graduando do curso de Engenharia Ambiental e Sanitária, Faculdades Integradas de Três Lagoas AEMS. E-mail: diegomoreno0007@gmail.com.

${ }^{3}$ Mestre em Geografia (UFMS/CPTL), Professor das Faculdades Integradas de Três Lagoas - AEMS. E-mail: andreluisvf@gmail.com.
} 


\section{Periádica Eletranica

change of people, being essential to reverse this reality, educating them and showing the value and importance of water resources.

KEYWORDS: Surface and ground waters. Hydrological cycle. Water shortage.

\section{LA IMPORTANCIA DE LA PRESERVACIÓN Y CONSERVACIÓN DE AGUA SUPERFICIAL Y SUBTERRÁNEA: PANORAMA GENERAL SOBRE LA ESCASEZ DE AGUA EN BRASIL.}

\section{RESUMEN}

En la actualidad, la falta de agua afecta a miles de personas en todo el mundo, así como de varias regiones brasileñas que ya sufren de escasez. En este sentido, el presente trabajo tiene como objetivo demostrar la importancia biológica, económica y social del agua, el aumento de la apreciación de la calidad de las aguas superficiales y subterráneas, con énfasis en la preservación y conservación. La metodología se basa en la técnica de recolección de datos de la investigación básica y exploratoria y cómo, la búsqueda bibliográfica. Se dio cuenta de que en el siglo XXI, las personas de una manera general, todavía no pagados adecuadamente atención cuando se trata del medio ambiente causado problemas, y sobre todo con la escasez de agua. Por lo tanto, es necesario un cambio inmediato en el hábito y las costumbres de la gente, siendo esencial para revertir esta realidad, educándolos y mostrando el valor y la importancia de los recursos hídricos.

PALABRAS-CLAVE: Aguas superficiales y subterráneas. Ciclo hidrológico. Escasez de agua.

\section{INTRODUÇÃO}

A água é um elemento vital e de suma importância na vida do ser humano, não apenas para a sua sobrevivência, mas também para o desenvolvimento de várias atividades, tais como: geração de energia, produção industrial, transporte fluvial, diluição de efluentes domésticos e industriais, captação de água para potabilização, e especialmente, a manutenção do equilíbrio das condições ecológicas e ambientais.

O Brasil é um país de grande representatividade na questão de recursos de águas superficiais da América do Sul, totalizando cerca de 50\% desses recursos, o que totaliza $11 \%$ em termos de volume a nível mundial, apesar de não ser uma distribuição uniforme (TUCCI; HESPANHOL; CORDEIRO NETTO, 2000).

Essa grande disponibilidade da água em nosso país não se resume apenas o seu aspecto quantitativo. Os vários usos da água possuem requisitos de qualidade, que, quando não atendidos, representam um fator limitante para o seu aproveitamento (ANA, 2012). 
Apesar de ser um recurso renovável do planeta e composto de ligação dos ecossistemas e subsistemas ambientais, pode-se considerar a água como um recurso natural e limitado, sendo que a porção de água doce disponível no mundo é muito pequena, cerca de 2,5\% (GIAMPÁ; GONÇALES, 2005).

Por outro lado, a crise da água no Planeta gera diversas preocupações tanto para políticos como para a sociedade. A discussão sobre a escassez da água desperta interesses por parte da população que busca por medidas que possa reverter essa situação. $O$ desenvolvimento sem um planejamento ambiental adequado é um fator preocupante, já que se sabe que ainda há poucas regiões no mundo livre dos problemas da perda de fontes potenciais de água, da degradação da qualidade da água e da poluição das fontes superficiais e subterrâneas (DI BERNANDO; DANTAS, 2005).

Segundo Ana (2012), a degradação dos corpos d'águas vem ocorrendo, em intensidades e tempos variados, em grande parte dos centros urbanos brasileiros. Os impactos dessa degradação têm reflexos econômicos, tais como: o aumento do custo de tratamento das águas destinadas ao consumo, o aumento de custos hospitalares com internações, a perda de produtividade na agricultura e na pecuária, a redução de valores turísticos, culturais e paisagísticos.

Sabe-se que as ações antrópicas afetam e alteram a qualidade da água, levando a sua contaminação. A realidade atual nos leva a situações em que muitas pessoas, hoje, captam e consomem água superficial sem nenhum tratamento. Apesar de inadmissíveis, fatos assim fazem parte do cotidiano de diversas comunidades (HELLER; PÁDUA, 2006). Atualmente, observou-se o caos no estado de São Paulo com a problemática da falta d'água. Apesar de possuir vários cursos d'águas, a maioria encontra-se poluídos.

Vale lembrar que, uma alternativa de captação de água é a subterrânea, já que as águas superficiais encontram-se parcialmente contaminadas, assim ocorrendo a maior incidência do uso das subterrâneas, que por sua vez vem correndo sério risco de contaminação também, pelo fato do crescimento populacional indiscriminado e a falta de planejamento de certos municípios, onde há registro de diversas fossas negras e lixões, na qual não se tem o devido controle (GRASSI, 2001). 
O autor reforça ainda, a necessidade e a importância da preservação e conservação das águas superficiais e subterrâneas, uma vez que contaminadas é quase impossível à reversão do quadro.

Assim, este trabalho tem por objetivo demonstrar a importância biológica, econômica e social da água, despertando a valorização da qualidade das águas superficiais e subterrâneas, com ênfase na sua preservação e conservação, bem como gerar e utilizar conhecimento com a finalidade de promover a conscientização.

Para tanto, utiliza-se três situações distintas como forma de discussão do presente trabalho, sendo elas: crise da água em São Paulo; falta de água em municípios de Minas Gerais; e a problemática da água na Bacia Amazônica.

Portanto, pode-se constatar a relevância do desenvolvimento da pesquisa, numa visão contemporânea, relacionadas aos problemas de escassez ou falta de água no século XXI, como às questões ambientais de preservação e conservação desse recurso natural essencial para todos os seres vivos.

\section{2 ÁGUA NO GLOBO TERRESTRE}

A determinação da presença de água em quantidade durante seu ciclo é decorrente dos variados tipos de ambiente, por meio das variações climáticas, geográficas e pluviométricas.

Segundo Telles e Costa (2010, p.1), "a disponibilidade da água define a estrutura e funções de um ambiente responsável pela sobrevivência de plantas e animais, assim como todas as substâncias em circulação que constituem o ser vivo".

A água tem um importante papel nos seres vivos: manter a temperatura corporal estável, além de ser uma substância predominante e ajudar na eliminação de muitas substâncias.

"Considera-se, atualmente, que a quantidade total da água na Terra seja de 1.386 milhões de $\mathrm{km}^{3}$ em que $97,5 \%$ do volume total formam os oceanos e os mares e somente $2,5 \%$ constituem-se de água doce" (TELLES; COSTA, 2010, p.2).

Desses $2,5 \%$ em termos de volume, $68,9 \%$ correspondem às geleiras e as calotas polares. As águas subterrâneas correspondem a 29,9\% e a água disponível para uso, armazenada em rios e lagos constitui apenas 0,3\% (TUNDISI, 2003). 


\section{Periádica Eletranica

Assim, ressalta-se que, além de ser pequena a porcentagem de água doce na Terra, sua maior proporção se encontra em calotas polares e geleiras, gerando uma grande dificuldade para o seu aproveitamento.

Por ser o solvente universal, a água é capaz de dissolver substâncias orgânicas e inorgânicas nos seus três estados: sólido, líquido e gasoso. Algumas dessas substâncias são essenciais para a sobrevivência dos organismos aquáticos (BRAGA et al., 2005).

Portanto, nenhum ser vivo sobrevive sem água, principalmente se usada para consumo humano deverá atender seus padrões de qualidade (Portaria $\mathrm{n}$. o 2914, do Ministério da Saúde) para que possa ser potável, ou seja, ausente de substâncias dissolvidas e organismos patogênicos. Este consumo é dividido em três principais atividades: agricultura, indústria e urbano-domésticas.

\subsection{O Ciclo Hidrológico}

Para o Ministério do Meio Ambiente (2014, p.1):

O ciclo hidrológico, ou ciclo da água, é o movimento contínuo da água presente nos oceanos, continentes (superfície, solo e rocha) e na atmosfera. Esse movimento é alimentado pela força da gravidade e pela energia do Sol, que provocam a evaporação das águas dos oceanos e dos continentes. $\mathrm{Na}$ atmosfera, forma as nuvens que, quando carregadas, provocam precipitações, na forma de chuva, granizo, orvalho e neve.

O ciclo hidrológico tem o papel de repor a água doce encontrada no nosso Planeta, através da evaporação das águas oceânicas e da precipitação. O volume de água que circula pelas diversas regiões da Terra é muito variável e as regiões que possuem maiores ocorrências de chuva há um maior número de água, porém, regiões que têm menor incidência de chuva (secas) há uma diminuição da quantidade de água podendo gerar conflitos relacionados à escassez de água (GRASSI, 2001).

Sztibe e Sena (2004) explicam que, o ciclo hidrológico é a forma com que a água se movimenta pela Terra de uma altura sobre o solo de quinze quilômetros para uma profundidade de cinco quilômetros, caracterizado como sistema químico, transformando a água de certo reservatório para outro em ciclos, através da gravidade ou energia solar ao longo de variados períodos. Este sistema funciona através da evaporação da água dos oceanos, retornando na Terra em forma de 


\section{Periódica Eletranica

água doce através de chuva ou neve. Há uma renovação da água purificando suas impurezas e deixando-a potável para a utilização.

Ainda segundo os autores, ocorrerá uma rápida evaporação se o tempo for mais quente e seco. A junção de sublimação (evaporação de lagos, rios, solo, neve e gelo) com a transpiração (evaporação da água através dos poros das folhas de plantas) e a evaporação é chamada de evapotranspiração.

Todo esse processo alterna-se durante o tempo no espaço de forma a favorecer e alcançar o equilíbrio do ciclo hidrológico. Convém mencionar que, a transpiração dos organismos vivos juntamente com a evaporação terrestre somado às condições climáticas formam nevoeiros e nuvens que, pela ação da gravidade se precipitam em fase líquida e em fase sólida por condensação de vapor de água.

Seguindo-se, pois, a interação entre a precipitação e o solo, através da infiltração, do escoamento superficial e da percolação, contribui para a recarga de recursos hídricos em forma de fluxos de água subterrâneos e em descargas nos reservatórios superficiais.

\section{2 Águas Superficiais e Subterrâneas}

Para Silva (2007), os principais componentes do ciclo hidrológico são as águas superficiais e subterrâneas, caracterizadas como recursos hídricos aproveitados pelo homem.

A água retirada dos mananciais superficiais (rios, lagos ou represas) e dos poços (mananciais profundos), decorrentes do processo de captação, é enviada para estações de tratamento e consequentemente distribuída à população.

A infiltração no solo, devido à precipitação de água sobre a superfície geram as águas subterrâneas, que são armazenadas no interior das rochas e do solo. Caso haja falha de distribuição de outras fontes, as águas subterrâneas podem ser consideradas um recurso estratégico (SILVA, 2007).

Segundo Di Bernardo e Dantas (2005), do ponto de vista tecnológico, água de qualquer qualidade pode ser transformada em água potável, entretanto, os custos envolvidos e a confiabilidade na operação e manutenção pode inviabilizar completamente o uso de determinado curso d'água como fonte de abastecimento. 


\section{Periádica Eletranica

Nos últimos anos o Brasil aumentou o índice de captação de águas subterrâneas (TELLES; COSTA, 2010), especialmente pelo fato de que a qualidade das águas superficiais tem piorado gradativamente.

Sousa (2001) define água subterrânea como aquela que de várias formas, encontra-se no subsolo e/ou solo, acumulando em determinados locais e consequentemente gera reservas de água caracterizadas como mantos aquíferos ou aquíferos. Dependendo das formações geológicas, os meios onde a água se escoa apresentam características de porosidade e permeabilidade, classificando ainda os meios em permeável de alta escala ou baixa escala, ou seja, muito permeável ou pouco permeável.

Desse modo, a partir da verificação da capacidade de um aquífero, é feita a captação das águas subterrâneas em quantidade e qualidade. Entende-se que, as águas subterrâneas contribuem para o equilíbrio hidrológico e são consideradas como fonte indispensável para o consumo humano, podendo ser consideradas então como importante componente do ciclo hidrológico.

Contudo, a água subterrânea pode ser definida como águas que através da infiltração e percolação pelas camadas do solo e rochas, ficando armazenadas em seus interiores gerando reservas de águas denominadas aquífero.

Por outro lado, as águas superficiais compreendem os rios, os lagos e as águas de torrentes, sendo excluídas devido a salinidade as águas dos oceanos, onde geram problemas em questão de captação da água superficial nos aspectos qualitativos dizendo respeito a quantidade. As águas superficiais permitem, geralmente, maiores condições de captação por existirem em maior quantidade, porém apresentam condições de qualidade muito piores (SOUSA, 2001).

Silva (2007) salienta que as águas superficiais são águas que escoam ou são armazenadas na superfície terrestre, com a contribuição de precipitação, recarga de aquíferos ou escoamento de corpos de água superficial. É a fonte mais fácil de captação humana, representando uma importante reserva de água, porém em questão de distribuição global representa uma pequena parcela. 


\section{Periódica Eletrânica

\section{METODOLOGIA}

A metodologia baseou-se na pesquisa básica que "objetiva gerar conhecimentos novos úteis para o avanço da ciência sem aplicação prática prevista. Envolve verdades e interesses universais" (PRODANOV; FREITAS, 2013, p. 51).

Quanto aos procedimentos técnicos, se enquadra na pesquisa bibliográfica, investigação do conhecimento teórico do tema água e sua importância como recurso natural esgotável, assim como a preservação e conservação.

Prodanov e Freitas (2013, p.54), definem pesquisa bibliográfica:

Quando elaborada a partir de material já publicado, constituído principalmente de: livros, revistas, publicações em periódicos e artigos científicos, jornais, boletins, monografias, dissertações, teses, material cartográfico, internet, com o objetivo de colocar o pesquisador em contato direto com todo material já escrito sobre o assunto da pesquisa.

Quanto aos objetivos gerais, teve caráter exploratório a fim de promover considerações, proposições e questionamentos com o intuito de gerar contribuições ao estudo. Finalmente, a partir das discussões, apontam-se algumas perspectivas para a realização de novas pesquisas, destinados a contribuir e enriquecer o conhecimento sobre a importância da preservação e conservação da água.

\section{RESULTADOS}

\subsection{Enfrentando a Escassez no Século XXI: A situação da água no Brasil.}

Para Braga et al. (2005), a escassez não é um fenômeno apenas de regiões áridas e semiáridas, pode-se dizer que em diversas regiões onde os recursos hídricos estão presentes de forma abundante, mas muitas vezes não suficiente para atender a demanda do local, devido à falta de água, ocasionalmente verifica-se problemas em relação ao desenvolvimento econômico e qualidade de vida.

Assim, apresentam-se três situações distintas para demonstrar a situação de escassez ou falta de água no Brasil, sendo elas: crise da água em São Paulo; falta de água em municípios de Minas Gerais; e a problemática da água na Bacia Amazônica. 


\section{Periódica Eletrânica

\subsubsection{Crise da água em São Paulo}

Pode-se citar a bacia do Alto Tiete, que tem como uma população superior a 15 milhões de habitantes, e um dos maiores complexo industriais do mundo, sendo que o manancial de abastecimento tem característica de manancial de cabeceira, sendo este não suficiente para atender esta região.

Os fatores da falta de água em diversos municípios, podem ser a falta de uma gestão pública consciente, a falta de planejamento, o consumo em excesso por parte dos moradores, e os fatores climáticos (CALIXTO; IMERCIO, 2014).

Calixto e Imercio (2014) relata que a crise em São Paulo, se deve em partes a falta de chuvas nas cabeceiras dos rios que abastecem o Sistema Cantareira. 0 Sistema Cantareira é um conjunto de represa responsável pelo abastecimento de aproximadamente 9 milhões de pessoas, sendo este sistema dependente das chuvas de verão. No inverno, período seco, as chuvas não passam de $150 \mathrm{~mm}$, por sua vez compensado no verão que no primeiro trimestre chove algo em torno de $600 \mathrm{~mm}$, porém, desde o ano passado, as chuvas não vêm no volume esperado (Figura 1).

Figura 1: Reservatório do Sistema Cantareira em Bragança Paulista.

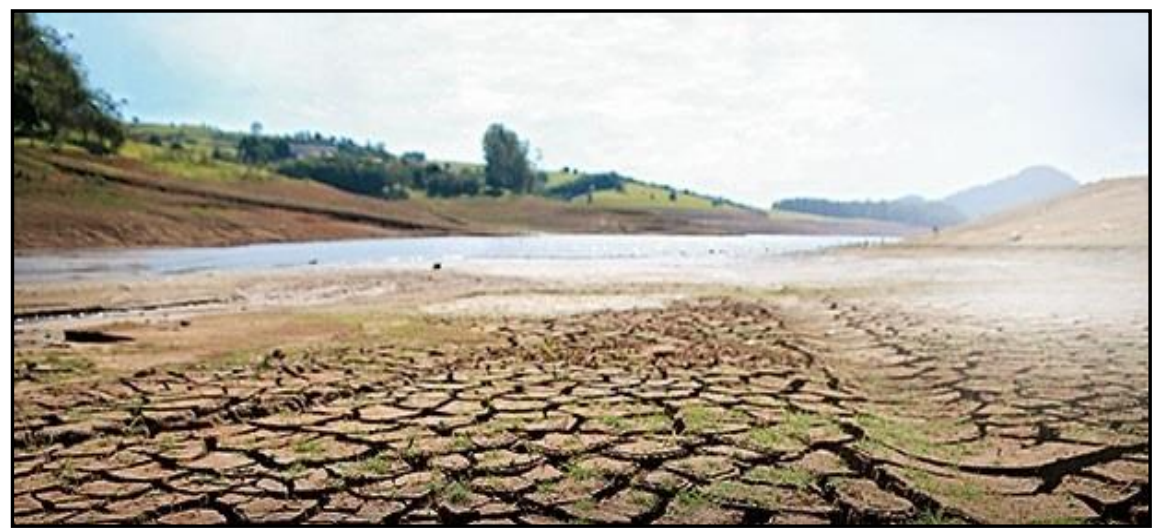

Fonte: Luis Moura/Estadão Conteúdo apud Calixto e Imercio (2014).

Os autores enfatizam ainda que para se ter uma ideia da situação, desde o ano de 2013 os índices pluviométricos já vinham abaixo da média normal, se agravando nos meses de outubro e novembro. Em janeiro e março de 2014, não choveu metade da média esperada, ou seja, não atingiu a marca dos $300 \mathrm{~mm}$.

O governo estadual coloca a culpa na falta de chuva, mas ela não explica a história sozinha. A estiagem deste ano apenas tornou evidente quanto o sistema é 


\section{Periádica Eletrânica

frágil e quão escassa a água é, mesmo num país tropical. [...] (CALIXTO e IMERCIO, 2014). Nesse sentido, cita-se a represa cachoeira, em Piracaia (Figura 2).

Figura 2: Represa Cachoeira, em Piracaia em 28/04/2010 e 11/03/2014.

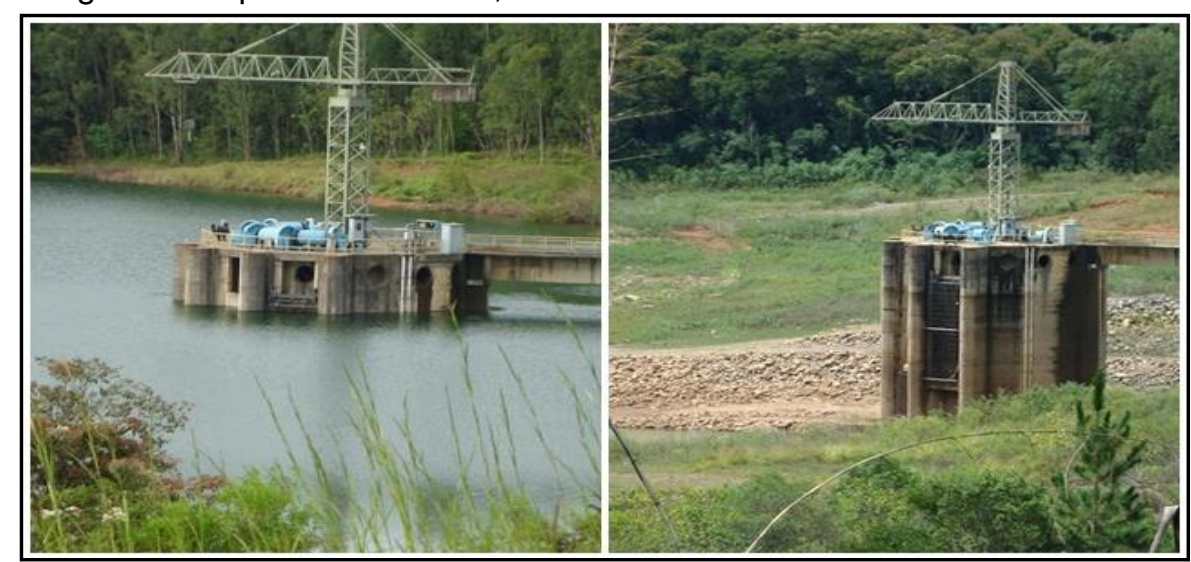

Fonte: RAC, 2014.

Ainda segundo os autores, o sistema existe desde a década de 70, onde se utiliza a água das bacias dos Rios Capivari, Jundiaí e Piracicaba, onde em 2004 a Sabesp, empresa responsável pelo abastecimento de água da capital e outra cidades, iniciou um trabalho com obras de engenharia para aumentar o volume do sistema, onde conseguiu renovar a autorização para utilizá-lo. Sendo permitida pelo governo estadual a retirada de 36.000 litros de água por segundo, para abastecimento das cidades, sendo deste a maior parte destinada a Grande São Paulo.

\subsubsection{Falta de água em municípios de Minas Gerais}

Para Pedrosa e Ariadne (2014, p.1), "o rio São Francisco, que abastece inúmeras cidades mineiras, sofre com a falta de chuva e está seco em vários pontos: as previsões de melhora no cenário são cada vez mais pessimistas" (Figura 3). 


\section{Periódica Eletrânica

Figura 3: Rio São Francisco.

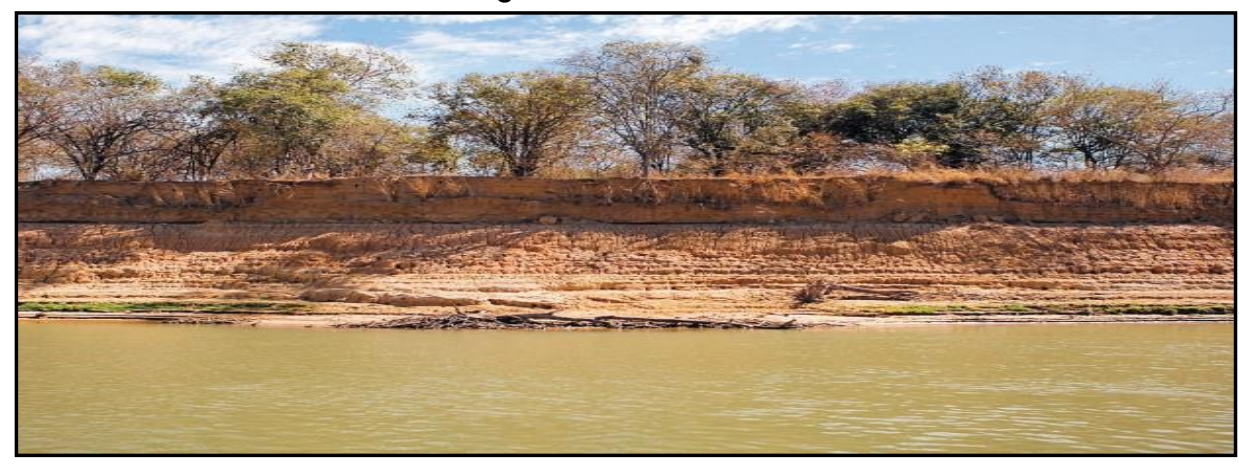

Fonte: PEDROSA e ARIADNE (2014).

Segundo a ANA, em relatório no Atlas Brasil - Abastecimento Urbano de Água ficou evidenciado que mais de 3000 cidades, ou $55 \%$ dos municípios brasileiros enfrentarão problemas com abastecimento de água no próximo ano (PEDROSA; ARIADNE, 2014).

Em Minas Gerais, a Copasa, que abastece 600 municípios, informou que a crise hídrica é a pior dos últimos cem anos. A empresa diz que, em média, a vazão dos rios do Estado caiu 40\%, mas há casos mais críticos e, em algumas cidades, a falta de água já é uma realidade (PEDROSA; ARIADNE, 2014, p.1).

De acordo com as autoras, diversas cidades já estão operando no sistema de racionamento, sendo que em Sete Lagoas as interrupções prontamente assustam moradores. O mesmo sistema, também foi implantado no Triângulo Mineiro, na cidade de Uberaba, onde a prefeitura decretou estado de emergência, e durante o dia houve diversos registros de interrupções de água.

Para Di Giaimo (2014), a principal causa da crise seria a grande estiagem, ou seja, a seca que assolou o estado em 2014. Cerca de 140 municípios já decretaram situação de emergência, conforme aponta a Defesa Civil. Como é comum a falta de chuvas nos meses entre outono e inverno, não é tão alarmante, mas a falta de chuvas nos meses que compreendem o verão foi o que propiciou uma seca muito maior.

Um fato que ocorre no Parque Nacional da Serra da Canastra vem assustando, segundo Fraga e Nazaré (2014) a nascente do rio São Francisco secou, sendo este o primeiro registro do sumiço de água na história do rio. Mesmo que ainda não há ameaça ao rio, mas a longa seca preocupa (Figura 4). 
Figura 4: Nascente do São Francisco completamente seca.

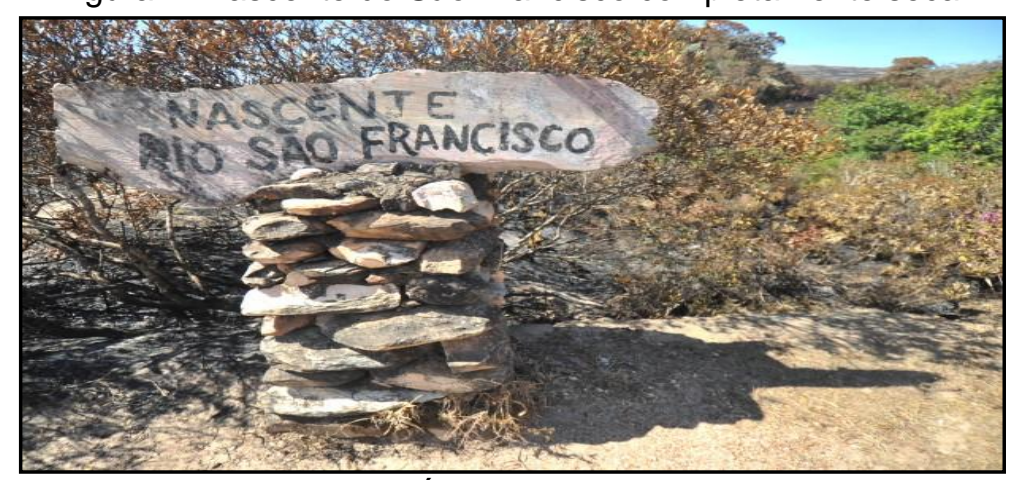

Fonte: FRAGA e NAZARÉ (2014).

De acordo com o Instituto Mineiro de Gestão das Águas (IGAM), além da nascente do Rio São Francisco, outros rios e reservatórios do estado de Minas Gerais estão com os níveis baixos (FRAGA; NAZARÉ, 2014).

A figura 5 ilustra o nível dos rios Paraíba do Sul e Rio Doce em Minas Gerais:

Figura 5: Nível de rios em Minas Gerais.

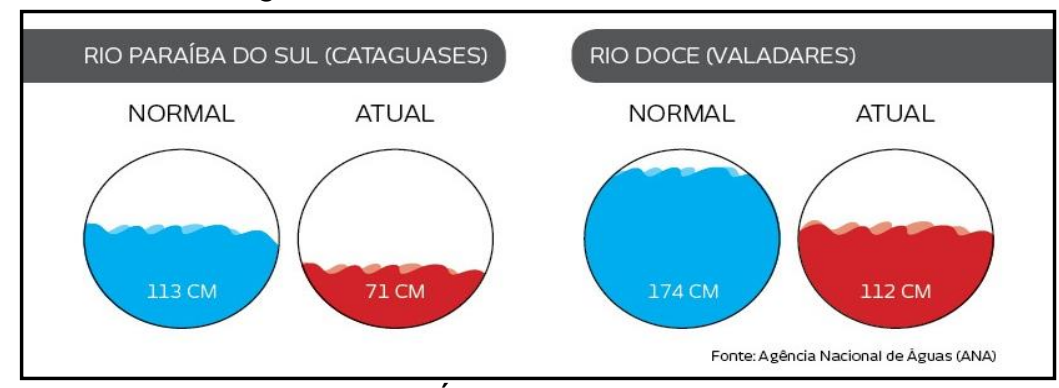

Fonte: FRAGA e NAZARÉ (2014).

"De acordo com a diretora de Pesquisa, Desenvolvimento e Monitoramento das Águas do órgão estadual, Ana Carolina Miranda, o problema é climático", uma vez que os últimos dois períodos chuvosos foram abaixo do normal (FRAGA; NAZARÉ, 2014, p.1).

\subsubsection{A Problemática da Água na Bacia Amazônica}

De acordo com Soares (2009), aproximadamente $70 \%$ da população que moram em cidades, enfrentam as mesmas dificuldades dos que moram em metrópoles do sudeste, a diferença é que na Amazônia o problema é maior. Quem vem de fora imagina a Amazônia uma região verde com muita água e diversas 


\section{Periádica Eletrânica

populações ribeirinhas ao seu longo. A problemática da Amazônia é maior do que se imagina, pois apenas $3,5 \%$ de sua população vivem em cidades, isso há quarenta anos, já hoje é algo em torno de $73 \%$.

Ainda falta água encanada, na região que concentra a maior parte da água doce do país, onde cerca de mais de $90 \%$ dos municípios não possui aterros sanitários, sendo que os lixos são depositados em lixões a céu aberto, ou muitas vezes lançados nos rios (SOARES, 2009).

A figura 6 ilustra palafitas da favela Igarapé do 40, em Manaus:

Figura 6: Esgoto e lixo lançados diretamente sobre os rios.

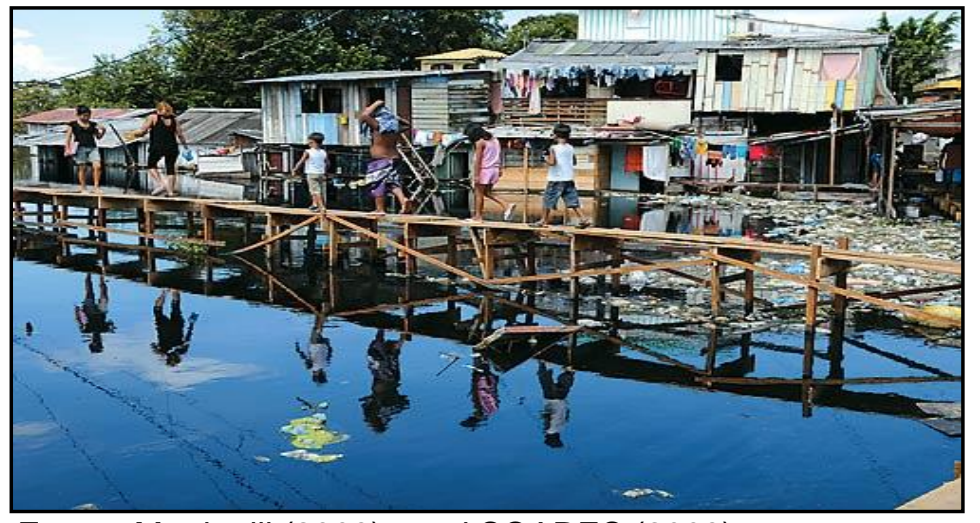

Fonte: Martinelli (2009) apud SOARES (2009).

Soares $(2009$, p.1) enfatiza a problemática na Amazônia: "O isolamento é um dos aspectos mais cruéis da vida na Amazônia, onde 5\% dos brasileiros se espalham por $60 \%$ do território nacional. Um terço dos amazônidas vive em áreas nas quais o estado não se preocupa em fornecer luz, água potável, serviços de saúde e escolas".

\section{CONSIDERAÇÕES}

Em pleno século $X X I$, nota-se que as pessoas de modo geral, ainda estão desligadas quando o assunto é problemas causados ao meio ambiente, e, sobretudo, o problema da escassez da água, ocasionado principalmente pela degradação dos corpos d'água. Infelizmente ainda existe uma falsa ideia de que os recursos hídricos são infinitos, apesar do aumento da população e poluição ambiental serem fatores comprometedores ao uso da água.

Visto a importância da água para a existência dos seres vivos, torna-se necessário uma mudança imediata no hábito e nos costumes das pessoas, sendo 
importante inverter essa realidade, conscientizando-as, mostrando o valor e a importância dos recursos hídricos.

A população em geral têm a responsabilidade em assumir individualmente a preservação e o uso consciente ao desfrutar os recursos naturais, de forma a não prejudicar as gerações futuras e agredir o meio ambiente.

Ao invés de utilizar os recursos hídricos para suprir as necessidades, o ser humano tem usado para outros fins, alterando sua qualidade e reduzindo a disponibilidade desses recursos, resultando em vulnerabilidade e desequilíbrio.

A água é essencial à manutenção da vida, devendo estar disponível em quantidade e qualidade suficiente para atender as comunidades. Dessa maneira, ressalta-se que a população necessita de conscientização com relação à utilização dos recursos hídricos, bem como os cursos d'água e o solo de bacias hidrográficas de modo a evitar as adversidades do abastecimento.

\section{REFERÊNCIAS}

ANA. Agência Nacional de Águas. Panorama da qualidade das águas superficiais do Brasil. Brasília: ANA, 2012.

BRAGA, B. et al. Introdução à Engenharia Ambiental. 2ª ed. São Paulo: Prentice Hall, 2005.

BRASIL. Ministério do Meio Ambiente. Recursos Hídricos. Águas Subterrâneas: Ciclo Hidrológico. Disponível em: <http://goo.gl//ISVt7>. Acesso: 08 abr. 2014.

CALIXTO, Bruno; IMERCIO, Aline. Crise da água em São Paulo: Quanto falta para o desastre? Revista Época, São Paulo, 16 jun. 2014. Disponível em: <http://goo.gl/1ol5xl>. Acesso em: 15 out. 2014.

DI BERNARDO, Luiz; DANTAS, Ângela Di Bernardo. Métodos e técnicas de tratamento de água. $2^{\mathrm{a}}$ ed. São Carlos: Rima, 2005.

DI GIAIMO, Maiara. Seca: Situação crítica em Minas Gerais. Clima Tempo. São Paulo, 2014. Disponível em: <http://goo.gl/5nnFMy>. Acesso em: 13 ago. 2014.

FRAGA, Marcelo; NAZARÉ, Fernanda. Seca ameaça Minas Gerais. Encontro notícias. Belo Horizonte, MG, 24 set. 2014. Disponível em: <http://goo.gl/pE2kkQ>. Acesso em: 13 out. 2014.

GIAMPÁ, Carlos Eduardo Quaglia; GONÇALES, Valter Galdiano Gonçales. Orientações para a utilização de Águas Subterrâneas no Estado de São Paulo - Setembro de 2005. Disponível em: $<$ http://goo.gl/HaHSog >. Acesso em: 16 dez. 2014.

GRASSI, Marco Tadeu. As águas do planeta Terra. Cadernos Temáticos de Química Ambiental. Química Nova na escola, n.․․ 1, maio, 2001.

HELLER, Léo; PÁDUA, Valter Lúcio de. Abastecimento de água para o consumo humano. Belo Horizonte: Editora UFMG, 2006. 


\section{Periódica Eletrânica

PEDROSA, Ana Paula; ARIADNE, Queila. Pesadelo da falta d'água já atinge metade dos municípios: Bairros de BH, Triângulo e Norte convivem com desabastecimento. Jornal O Tempo, Belo Horizonte, MG, 18 set. 14. Disponível em: <http://goo.gl/tiFjOe>. Acesso em: 13 out. 2014.

PRODANOV, Cleber Cristiano; FREITAS, Ernani Cesar de. Metodologia do Trabalho Científico: Métodos e Técnicas da Pesquisa e do Trabalho Acadêmico. $2^{\mathrm{a}}$ ed. Novo Hamburgo, RS: Universidade Feevale, 2013.

RAC. TÉCNICOS: eleição põe Cantareira em risco. RAC: IG Paulista, São Paulo, 13 mar. 2014. Disponível em: <http://goo.gl/rZAMYz>. Acesso em: 15 out. 2014.

SILVA, Ferdnando Cavalcanti da. Análise Integrada de usos de água superficial e subterrânea em macro-escala numa bacia hidrográfica: O caso do alto Rio Paranaíba. Porto Alegre: UFRS, 2007. Dissertação (Mestrado).

SOARES, Ronaldo. É preciso salvar também as cidades. Revista Veja, São Paulo, set. 2009. Disponível em: <http://goo.gl//FQXru>. Acesso em: 15 out. 2014.

SOUSA, Eduardo Ribeiro de. Saneamento Ambiental I: Captações de água. Lisboa: Departamento de Engenharia Civil e Arquitectura, setembro de 2001. Disponível em: <https://goo.gl/zYM5ik>. Acesso em: 15 out. 2014.

SZTIBE, Rosely; SENA, Lúcia Bastos Ribeiro de. Gestão Participativa das Águas. Secretaria de Meio Ambiente. Coordenadoria de Planejamento Ambiental Estratégico e Educação Ambiental. Departamento de Educação Ambiental. São Paulo: SMA/CPLEA, 2004.

TELLES, Dirceu D’Alkmin; COSTA, Regina Helena Pacca Guimarães (Orgs.). Reuso da água: conceitos, teorias e práticas. 2. ed. rev. atual. e ampl. São Paulo: Edgard Blucher, 2010.

TUCCI, C. E. M.; HESPANHOL, I.; CORDEIRO NETTO, O. de M. A gestão da água no Brasil: uma primeira avaliação da situação atual e das perspectivas para 2025. Janeiro/2000. Disponível em: <http://goo.gl/Veq4W4>. Acesso em: 15 out. 2014.

TUNDISI, J. G. Água no Século XXI: Enfrentando a Escassez. RIMA, IIE, 2003. 